\title{
Kısıntılı Sulama Uygulamalarının Ayçiçeği Bitkisinin (Helianthus annuus L.) Tane Verimi ve Bitki Su Stres İndeksi (CWSI) Üzerine Etkileri
}

\author{
Ali Beyhan Uçak ${ }^{1 *}$, M. Cüneyt Bağdatlı ${ }^{2}$, Hasan Değirmenci ${ }^{3}$ \\ ${ }^{1}$ Siirt Üniversitesi, Ziraat Fakültesi, Biyosistem Mühendisliği Bölümü, Siirt, Türkiye \\ ${ }^{2}$ Nevşehir Hacı Bektaş Veli Üniversitesi, Mühendislik Mimarlık Fakültesi, Biyosistem Mühendisliği Bölümü, \\ Nevşehir, Türkiye \\ ${ }^{3}$ Kahramanmaraş Sütçü İmam Üniversitesi, Ziraat Fakültesi, Biyosistem Müh. Bölümü, Kahramanmaraş, Türkiye \\ *1 alibeyhanucak@gmail.com, ${ }^{2}$ cuneytbagdatli@gmail.com, ${ }^{3}$ degirmanci@ksu.edu.tr
}

(Geliş/Received: 24/09/2017;

Kabul/Accepted: 22/01/2020)

Öz: Bu araştırma Siirt iklim koşullarında damla sulama yöntemiyle kısıntılı sulama uygulamalarının ayçiçeği bitkisinde verim ve verim parametreleri ile bitki su stres indeksi üzerine etkilerini belirlemek amaciyla bir tarla çalışması olarak yapılmıştır. Araştırmada sulama konuları; sulama suyu ihtiyacının tam olarak karşılandığı (\%100) (I100) kontrol konusu ve tam sulamadan \%80 ( $\left.\mathrm{I}_{20}\right), \% 60\left(\mathrm{I}_{40}\right), \% 40\left(\mathrm{I}_{60}\right)$ ve \%20 ( $\left.\mathrm{I}_{80}\right)$ oranında kısıntı yapılan dört sulama konusu ve hiç sulama suyu uygulanmayan $\mathrm{I}_{0}$ sulama konularından oluşturulmuştur. Yapılan istatistik analiz sonucunda verim ve verim parametreleri arasında istatistiksel olarak önemli düzeyde ilişkiler saptanmıştır. Sulama konularının verim ve verim bileşenleri üzerine etkisi \%1 düzeyinde önemli bulunmuştur. Uygulanan su kısıntısına ve iklim şartlarına bağlı olarak, ayçiçeği bitkisinin bitki su tüketimi, bitki su stres indeksi, klorofil ve verim değerleri önemli ölçüde etkilenmiştir. Vejetasyon süresi boyunca en yüksek CWSI (Bitki Su Stres Indeksi) değeri $I_{0}$ sulama konusunda 0.39 ve en düşük CWSI değeri tam sulanan $I_{100}$ sulama konusunda 0.19 olarak belirlenmiştir. Araştırmada ayçiçeği dane veriminin düşmeye başladığı, sulamadan önceki infrared termometre gözlemlerinden belirlenen eşik CWSI değeri 0.29 olarak belirlenmiştir. Yapılan bu çalışmanın sonuçlarına göre Siirt'te ayçiçeğinde kısıntılı sulama yapılması önerilmemekte veya kısıntı yapma zorunluluğu olduğu takdirde ise bunun vejetatif gelişme döneminde (çiçeklenme öncesinde) maksimum \%20 oranında yapılması önerilmektedir.

Anahtar kelimeler: Kısıntılı Sulama, Bitki su stres indeksi, Ayçiçeği

\section{The Effects on Crop Water Stress Index(CWSI) and Grain Yields of Sunflower Plant (Helianthus annuus L.) of Deficit Irrigation Applications}

\begin{abstract}
This research was conducted as a field study to determine effects on yield and yield parameters of sunflower plants and plant water stres index of deficit irrigation with drip irrigation applications of Siirt climate conditions. Irrigation issues in research; 1 full irrigation ( $\mathrm{I}_{100}$ control subject) and full irrigation $80 \%\left(\mathrm{I}_{20}\right), 60 \%\left(\mathrm{I}_{40}\right), 40 \%\left(\mathrm{I}_{60}\right)$ and $20 \%$ ( $\left.\mathrm{I}_{80}\right)$ rate cuts made four irrigation and is formed from no irrigation water is not applied $\mathrm{I}_{0}$. It made a statistically significant relationship between the yield and yield parameters were determined as a result of statistical analysis. Effect on yield and yield components of irrigation was significant at the $1 \%$ level and has been affected at different levels. Depending on the applied water shortages and climatic conditions, evapotranspiration of sunflower plants, plant water stres index, chlorophyll and yield is greatly affected. CWSI highest value during the vegetation period $0.39, \mathrm{I}_{0}$ the lowest value in the CWSI for irrigation is set at 0.19 in fully irrigated $\mathrm{I}_{100}$. In the study of sunflower grain yield began to decline, the CWSI threshold value determined from the previous infraret thermometer observations from irrigation has been identified as 0.29 . According to the study's results made it is not recommended to do or make cuts in Siirt deficit irrigation on sunflower must have if it is the vegetative stage (before flowering) is made up of $20 \%$ is recommended.
\end{abstract}

Key words: Deficit irrigation, Crop water stress index, Sunflower

\section{Giriş}

Ülkemizde toplam ayçiçeği ekim alanı 500-550 bin ha, üretim 725 bin ton ve ihtiyacımız 1 milyon ton civarındadır [1]. Ülkemizin toplam yağ gereksinimi 1.200-1.500 bin ton arasında görülmektedir [2]. Ancak Türkiye'nin yıllık ham yağ ithalatı ile yağlı tohum ithalatı her geçen yıl artmaktadır. 2003 yılı verilerine göre 853.540 ton bitkisel ham ve rafine yağ ve 1.401 .623 ton yağlı tohum ithalatı yapılmıştır. 2001 yılında yağlı tohum işleyen fabrikaların birçoğunun kapanması sebebiyle ham yağ ithalatında önemli bir artı̧̧ olmuştur [3].

\footnotetext{
*Sorumlu yazar: alibeyhanucak@ gmail.com, Yazarların ORCID Numaras1: ${ }^{10000-0003-4344-2848, ~}{ }^{20000-0003-0276-443}$
} 
Ayçiçeği bitkisi genel olarak oluşturduğu güçlü kök sistemi nedeniyle kurağa dayanıklı olarak bilinmekte ve kuru koşullarda yetiştirilmektedir [4,5]. Ancak yağışlarla alınan su miktarı yeterli değilse, yüksek verim alınması için sulama yapmak gereklidir. Bitkinin büyüme dönemlerinde ortaya çıkan uzun süreli kuraklıklar tablanın küçülmesine, tabladaki tane sayısının azalmasına ve bunun sonucu olarak da tane veriminin düşmesine neden olmaktadır [6]. Güneydoğu bölgesinde genellikle yazlık olarak kuru koşullarda tarımı yapılan ayçiçeği bitkisinin son yıllarda üretimi artma yönünde bir eğilim göstermiştir. Ayçiçeği yağlı tohumlar içerisinde adaptasyonu en yüksek tür olup, çok farklı çevre şartlarına kolaylıkla uyum sağlamaktadır. Ancak Güneydoğu gibi yarı kurak iklim kuşağı içerisinde yer alan bölgelerimizde yağış rejiminin düzenli olmaması, düşen yağışında homojen bir dağılım göstermemesi diğer tarla bitkilerinde olduğu gibi ayçiçeği yetiştiriciliğinde bir risk oluşturmakta ve sulama verimi etkileyen en önemli parametrelerden birisi olmaktadır.

$\mathrm{Bu}$ çalışma orta oleik yă̆ asidi özelliklerine sahip ayçiçeği (P64LL62) genotipinin kısıntılı sulama uygulamaları altında, su kullanım randımanı ile su stresinin bitki su tüketimine ve verim üzerine etkilerini belirlemek ve yetişme sezonu boyunca kaç sulama uygulamasını yapılması gerektiğini tespit etmek amacıyla bir tarla çalışması olarak yürütülmüştür.

\section{Materyal ve Yöntem}

\subsection{Materyal}

Denemede bitki materyalini orta oleik yă̆ asidi özelliklerine sahip (P64LL62) ayçiçeği genotipi oluşturmuştur. Deneme, açık tarla koşullarında 2014 yılında Siirt Üniversitesi Ziraat Fakültesi deneme sahasında yürütülmüştür. Deneme alanının denizden ortalama yüksekliği $894 \mathrm{~m}$ olup, $37^{\circ} 58^{\prime} \mathrm{N}$ enlemi ve $41^{\circ} 50^{\prime} \mathrm{E}$ boylamlarında yer almaktadır. Araştırma alanının yeri ve konumu Şekil 1'de görülmektedir.

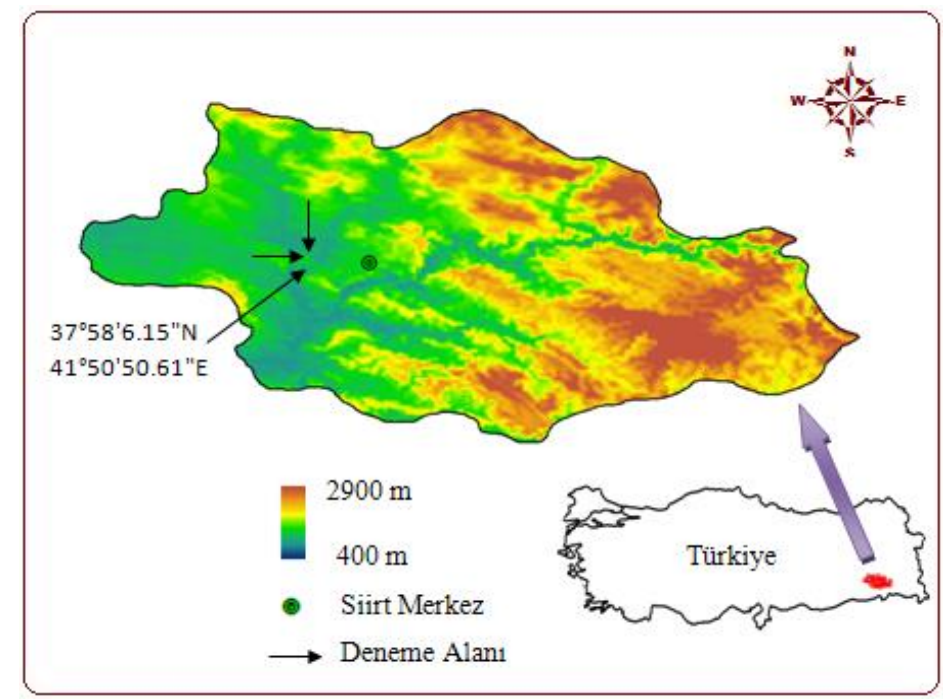

Şekil 1. Araştırma alanının yeri ve konumu

Siirt ilinde kara iklimi hüküm sürmekte olup, yazlar sıcak ve kurak, kışlar soğuk ve yağışlı geçmektedir. Yıllık yağış ortalaması $757 \mathrm{~mm}$, sıcaklık ortalaması ise $16.1{ }^{\circ} \mathrm{C}$ 'dir. Ancak yağış yıl boyunca düzenli bir dağılım göstermemekte ve ayçiçeği bitkisinin yetişme sezonu boyunca ise hemen hiç yağış düşmemektedir. Siirt lokasyonu deneme arazisi toprağının elektriksel iletkenliği düşük olup tuzluluk sorunu bulunmamaktadır, kireç oranının bitki yetiştiriciliği açısından sorun oluşturmadığı, fosfor içeriği düşük, potasyum içeriğinin yüksek ve organik madde oranının orta derecede bulunduğu killi bünyeli toprak yapısında olup, tarla kapasitesi (TK) derinlik cinsinden $397 \mathrm{~mm}$, solma noktası (SN) $277 \mathrm{~mm}$, hacim ağırlığı $1.43 \mathrm{gr} \mathrm{cm}^{-3}$ olarak hesaplanmıştır.

\subsection{Yöntem}

Deneme Siirt Üniversitesi Ziraat Fakültesi arazisinde 11 Nisan 2014 tarihinde kurulmuştur. Parsel uzunluğu $6 \mathrm{~m}$, parsel genişliği $2.1 \mathrm{~m}$, sıra arası mesafe $70 \mathrm{~cm}$ ve sıra üzeri mesafe $30 \mathrm{~cm}$ olmak üzere, ekilen her bir parsel 
alanı $(0.7 \mathrm{~m} \mathrm{x} 6 \mathrm{~m} \mathrm{x} 4$ sıra $) 16.8 \mathrm{~m}^{2}$ olarak planlanmıştır. Denemeler tesadüfi bloklarında bölünmüs parsel deneme desenine göre ü̧̧ tekerrürlü olacak şekilde kurulmuş ve Şekil 2'de verilen plan doğrultusunda yürütülmüştür.

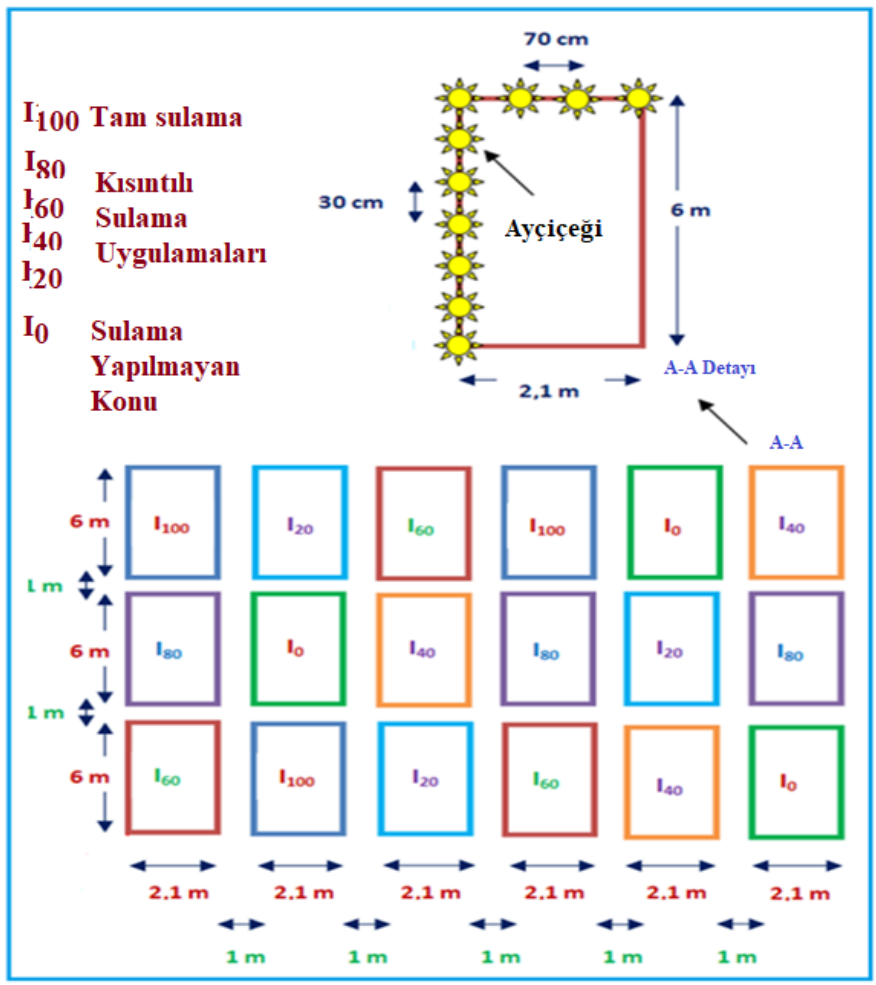

Şekil 2. Deneme uygulama planı

Çalışmada $45 \mathrm{~kg} \mathrm{da}^{-1}$ 20-20-0 kompoze gübre kullanılmıştır. Vejetasyon süresi boyunca, 4 sulama yapılmıştır. Sulama aralığı elverişli nemin \%50'ye düștüğü $0-90 \mathrm{~cm}$ derinliğindeki toprak nem düzeyi olarak seçilmiştir. Deneme parsellerinin sulanması, damla sulama yöntemi ile yapılmıştır ve sulama suyu sayaçlardan geçirilerek uygulanmıştır. Sulama suyunun kalitesi $\mathrm{C}_{2} \mathrm{~S}_{1}$ olarak saptanmıştır. Denemede kullanılan sulama suyu ayçiçeği bitkisinin sulanması açısından bir sorun oluşturmamaktadır.

Hasat, fizyolojik olumun tamamlandığ danedeki nem \%10'a düştüğünde, her parsel kenarındaki ikişer sıra kenar tesiri olarak işlem dışı bırakılıp, orta iki sıradan el ile yapılmıștır. Deneme süresince, gerekli bakım işlemleri ve kültürel uygulamalar standart yöntemlere göre yapılmıştır. Elde edilen verilerin değerlendirilmesinde, JUMP istatistik bilgisayar paket programı kullanılarak, varyans analizi ve F-kontrolü yapılmıştır. Ortalamalar LSD-Testi yapılarak karşılaşıtırılmıştır.

\subsubsection{Bitki su stresi indeksi (CWSI) ve klorofil içeriği}

Bitki su stresi indeksi (CWSI) araştırmacıların önerdiği ampirik yöntemle belirlenmiştir [7]. Anılan yönteme göre CWSI şu eşitlikle tanımlanmıştır.

CWSI $=[(T c-T a)-L L] /$ UL- LL

Eșitlikte; Bitki Su Stresi İndeksi (CWSI), Tc, taç sıcaklığ $1\left({ }^{\circ} \mathrm{C}\right)$; Ta, hava sıcaklığ $\left({ }^{\circ} \mathrm{C}\right) ; \mathrm{LL}$, bitkide su stresinin olmadığı alt sınır (bitkilerin potansiyel hızda transpirasyon yaptığı sınır değeri); UL, bitkilerin tamamen stres altında olduğu üst sınırı (bitkinin transpirasyon yapmadığı varsayılan sınır değeri) göstermektedir.

Söz konusu deneme konuları için her sulama konusunda meydana gelen bitki su tüketimi $90 \mathrm{~cm}$ toprak derinliği göz önüne alınarak su dengesi esasına göre hesaplanmıștır. Bu amaçla söz konusu periyodun başlangıcındaki toprak nemi miktarına o periyot içerisinde varsa uygulanan sulama suyu miktarı ve etkili yağı̧̧ değerleri eklenmiş, toplamdan periyot sonundaki toprak nemi değeri çıkarılmıştır [8]. 
Klorofil içeriği, yapraktaki klorofil miktarını dolaylı olarak ölçen, taşınabilir klorofil metre cihazı (Minolta SPAD- 502, Osaka, Japan) ile yapılmıştır.

Klorofil ölçümleri tüm yetişme sezonu boyunca farklı dönemlerde olmak üzere her parselde rastgele seçilen 10 adet ayçiçeği bitkisinin çiçek tablasına yakın yaprağında öğle $12:^{00}$ - 14:00 saatleri arasında açık havada, rüzgarsız günlerde yapılmış ve her parsel için ölçülen 10 bitkinin yaprağına ilişkin değerlerin aritmetik ortalaması alınarak ve o parselin yaprak klorofil içeriği spad cinsinden (cihazdan okunan değerler spad değeri olarak) saptanmıştır.

Anılan konuların yaprak klorofil içeriklerinin (spad) ifade edilmesinde 0-1 skalası kullanılmış olup bu değer 1'e yaklaştıkça klorofil içeriği artmakta, sıfıra 0'a yaklaştıkça azalmaktadır. Sulama suyu kullanım etkinliği ve sulama suyu etkinliğinin belirlenmesinde ise verim değeri uygulanan sulama suyu ve bitki su tüketimine bölünerek bulunmuştur.

\section{Araştırma Sonuçları ve Tartışma}

Toprak nemi $0-90 \mathrm{~cm}$ toprak profili boyunca gravimetrik yöntemle takip edilmiş olup sulama programı haftada bir olacak şekilde planlanmış ve tüm konular belirlenen oranlarda aynı gün sulanmıştır. Toplam 4 kez sulama suyu uygulanmış ve toplam uygulanan sulama suyu miktarı deneme yılında sırasıyla en düşük $I_{20}$ sulama konusuna $125 \mathrm{~mm}$, en yüksek $\mathrm{I}_{100}$ sulama konusuna $624 \mathrm{~mm}$ ve anılan konuların bitki su tüketimi sırasıyla en az $\mathrm{I}_{20}$ sulama konusunda $201 \mathrm{~mm}$ ve en fazla $\mathrm{I}_{100}$ sulama konusunda $703 \mathrm{~mm}$ olarak belirlenmiştir. $\mathrm{I}_{0}$ sulama konusuna ise can suyu hariç sulama suyu uygulaması yapılmamıştır. Sulama konularında bitki su tüketiminin kısmen de olsa yüksek bulunması ise deneme yılında ortalama ve maksimum sıcaklık değerlerinin uzun yıllara kıyasla kısmen de olsa daha yüksek olmasına bağlanabilir. Bir başka ifade ile daha fazla sulama suyu uygulanması ve evapotranspirasyonun yüksek olması ile ilişkilendirilebilir.

Hava sıcaklığının önceki yıllara göre daha yüksek nemin ise biraz daha düşük olması bitki su tüketimini artırıcı yönde etkide bulunduğu düşünülmektedir. Buna karşın tüm yörede verim bir önceki yıla göre kısmen de olsa azalmıştır. Araştırmada ekim işlemini takiben ve aynı gün topraktaki nem düzeyi homojen bir çıkış için (63 $\mathrm{mm}$ ) tarla kapasitesine (TK) getirilinceye kadar 1slatılmıştır. Bitki su stres indeks okumalarının ilki deneme alanının \%80'i bitki örtüsü ile kaplı olduğu dönemde, ekimden sonra 47. gün ve sonuncusu ise ekimden sonra 87. gün yapılmıştır. Diğer okumalar ise bu iki tarih arasında sulama öncesi ve sonrası olmak kaydıyla toplam altı farklı zamanda yapılmıştır.

\subsection{Bazı verim parametreleri}

Uygulanan sulama konularına ilişkin ayçiçeğinde belirlenen bazı verim parametrelerine ilişkin ortalama değerleri (LSD) Tablo 1'de verilmiştir.

Tablo 1. Uygulanan sulama konularına ilişkin ayçiçeğinde belirlenen bazı verim parametreleri

\begin{tabular}{c|c|c|c|c|}
\hline $\begin{array}{c}\text { Sulama } \\
\text { konusu }\end{array}$ & $\begin{array}{c}\text { Dane verimi } \\
\left(\mathrm{kg} \mathrm{da}^{-1}\right) \\
* *\end{array}$ & $\begin{array}{c}\% 50 \text { çiçeklenme } \\
\text { gün sayıs }(\mathrm{gün}) \\
* *\end{array}$ & $\begin{array}{c}\text { Bitki Boyu } \\
(\mathrm{cm}) \\
* *\end{array}$ & $\begin{array}{c}\text { Tabla } \\
\text { çap1 }(\mathrm{cm}) \\
* *\end{array}$ \\
\hline $\mathrm{I}_{0}$ & $139.0 \mathrm{~d}$ & $46.0 \mathrm{~d}$ & $103.0 \mathrm{~d}$ & $11.5 \mathrm{~d}$ \\
\hline $\mathrm{I}_{20}$ & $139.9 \mathrm{~d}$ & $46.5 \mathrm{~d}$ & $103 \mathrm{~d}$ & $11.6 \mathrm{~d}$ \\
\hline $\mathrm{I}_{40}$ & $178.3 \mathrm{c}$ & $47.3 \mathrm{c}$ & $129 \mathrm{c}$ & $12.9 \mathrm{c}$ \\
\hline $\mathrm{I}_{60}$ & $260.7 \mathrm{~b}$ & $54.3 \mathrm{~b}$ & $131 \mathrm{c}$ & $15.8 \mathrm{~b}$ \\
\hline $\mathrm{I}_{80}$ & $306.5 \mathrm{a}$ & $62.0 \mathrm{a}$ & $159 \mathrm{~b}$ & $17.0 \mathrm{a}$ \\
\hline $\mathrm{I}_{100}$ & $310.7 \mathrm{a}$ & $62.3 \mathrm{a}$ & $170 \mathrm{a}$ & $17.9 \mathrm{a}$ \\
\hline C.V. $(\%)$ & 3.38 & 1.5 & 1.81 & 3.54 \\
\hline LSD $(0.05)$ & 152.3 & 1.52 & 4.73 & 1 \\
\hline
\end{tabular}
(*) Aynı harfle gösterilen ortalamalar arasindaki fark önemli degildir. LSD sinflaması Prop ${ }^{* *}: \% 1$ düzey

Çiçeklenme Gün Sayısı: Çıkıştan itibaren her bir parseldeki bitkilerin \% 50 çiçeklenme (R.5.5) devresine ulaştığı zamandır. Parseldeki tüm bitkilerin durumu gözlemlenerek bitkilerin tamamına yakın kısmı bu devreye ulaştığı gün sayısı tespit edilmiştir. Ayçiçeği sulama konularında Çiçeklenme Gün Sayısı verilerine ilişkin ortalama değerler Çizelge 1'de verilmiştir. Çizelge 1'de görülebileceği gibi çiçeklenme gün sayısı bakımından sulama konuları arasında önemli farklılıklar tespit edilmiştir. 
Denemeye alınan ayçiçeğinde sulama konularına göre en erken çiçeklenme gün sayısı $\mathrm{I}_{0}$ ve $\mathrm{I}_{20}$ sulama konusunda 46.5 gün ve en geç çiçeklenme gün sayısı değeri $\mathrm{I}_{100}$ sulama konusunda 62.3 gün olarak belirlenmiştir. Çiçeklenme diğer sulama konularında ise bu iki tarih arasında değişmiştir. İlk çiçek açan sulama konusu ile son çiçek açan arasında 15 gün fark olduğu belirlenmiştir. Bu farkın kısıntılı sulama uygulamaları ile ilgili olduğu söylenebilir.

Bitki Boyu (cm):Örnek olarak alınan gelişmiş 5 bitkinin boyu toprak seviyesinden merkezi dalın sonunda bulunan çiçek tablasının altına kadar olan yükseklik $\mathrm{cm}$ olarak ölçülmüştür. Araştırmada sulama konularında bitki boyları 103 - $170 \mathrm{~cm}$ arasında değiştiği en yüksek bitki boyunun $\mathrm{I}_{100}$ sulama konusunda $170 \mathrm{~cm}$, en düşük bitki boyu ise $\mathrm{I}_{0}$ ve $\mathrm{I}_{20}$ sulama konusunda $103 \mathrm{~cm}$ olarak elde edilmişsir. Diğer sulama konularındaki bitki boyları ise bu iki değer arasında değişmiştir.

Tabla Çapı (cm): Örnek olarak alınan, gelişmiş 10 bitkinin tablalarına ait çaplar "cm" olarak ölçülmüştür. Araştırmada uygulanan sulama konularında tabla çapları 11.5 - $17.9 \mathrm{~cm}$ arasında değiştiği, en yüksek tabla çapının $\mathrm{I}_{100}$ sulama konusunda $17.9 \mathrm{~cm}$, en düşük tabla çapının ise $\mathrm{I}_{0}$ ve $\mathrm{I}_{20}$ sulama konusunda $11.5-11.6 \mathrm{~cm}$ olduğu saptanmıştır.

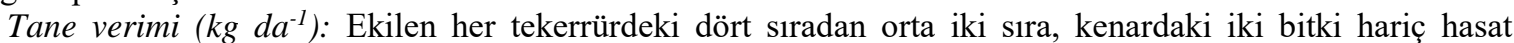
edilmiş olup, parsel hasat alanı $(0.7 \mathrm{~m}$ x $6.9 \mathrm{~m}) 4.83 \mathrm{~m}^{2}$ dir. Harman edilen taneler temizlenip tartılmıştır. Tartım anında tanedeki nem oranı John Dickey nem ölçüm cihazı ile belirlenmiş ve \% 10 neme göre hesaplanarak parsel verimi ve dekara verim bulunmuştur. Ayçiçeği sulama konularında tohum verimi $\left(\mathrm{kg} \mathrm{da}^{-1}\right)$ verilerine ilişkin ortalama değerler Çizelge 1'de sunulmuştur. Araştırmada, farklı sulama uygulamalarında tohum verimleri $310.7 \mathrm{~kg} \mathrm{da}^{-1}-139.9 \mathrm{~kg} \mathrm{da} \mathrm{da}^{-1}$ arasında değiştiği en yüksek tohum veriminin $\mathrm{I}_{100}$ sulama konusunda $310.7 \mathrm{~kg} \mathrm{da}^{-1}$, en düşük tohum veriminin ise $\mathrm{I}_{0}$ sulama konusunda $139.0 \mathrm{~kg} \mathrm{da}^{-1}$ olduğu belirlenmiştir.

Araştırmacılar ayçiçeği su-verim ilişkileri üzerine yaptıkları çalışmada tane verimini çalışmanın 1.yılında 80-233.20 kg da-1, ikinci yılında 85.35-273.38 kg da-1 olarak bulmuşlardır [6].

$\mathrm{Bu}$ çalışmadan elde edilen bulgular ile anılan araştırıcıların bulguları arasında kısmen de olsa farklılıklar bulunmaktadır. $\mathrm{Bu}$ farklılıkları iklim, toprak, çeşit ve uygulanan sulama programına bağlı olduğu düşünülmektedir.

Bitkinin büyüme periyotlarında ortaya çıkan uzun süreli kuraklıklar tablaların küçülmesine, tabladaki dane sayısının azalmasına, bunun sonucu olarak da dane veriminin düşmesine neden olmaktadır [9,10]. Ayçiçeği özellikle çiçeklenme periyodunda topraktaki nem eksikliğine karşı oldukça duyarlıdır. Sadece bu periyotta uygulanan sulama suyu bile dane ve yağ verimini önemli düzeyde arttırmaktadır [11,12].

Çiçeklenme ya da toplam vejetatif gelişme periyodunda su kısıntısı yapılması, başka bir deyişle bitkinin topraktaki nem eksikliğinden kaynaklanan gerilime girmesi dane ve yağ veriminde önemli düzeyde azalmalara neden olmaktadır. Bunun yanı sıra, tüm büyüme mevsimi boyunca \% 25 düzeyinde yada yalnız başına erken vejetatif gelişme, geç vejetatif gelişme ve dane oluşumu periyotlarından birinde su kısıntısı uygulanması durumunda dane ve yağ verimindeki azalma daha az olmaktadır [6]. Araştırmacılar araştırmalarında yağ verimi ve diğer tüm verim öğeleri arasında, yapılan regresyon analizleri sonucunda istatistikî açıdan önemli ilişkilerin olduğunu ortaya koymuştur [13].

En yüksek regresyon katsayısı beklenildiği gibi, tane verimiyle olmuş ve bu öğeyi bitki boyu, 1000 dane ağırlığı ve tabla çapı takip etmiştir. Yağ oranıyla yağ verimi regresyon katsayısının, araştırmada en düşük değerlerinden biri olarak hesaplanması yağ veriminin oluşumunda tane veriminin daha belirleyici rol oynadığını belirlemişlerdir.

\subsection{Sulama suyu kullanım etkinliği}

Kısıntılı sulama konularına ilişkin hesaplanan bitki su stres indeksi, klorofil içeriği, sulama suyu miktarları ile evapotranspirasyon, WUE ve IWUE değerleri Tablo 2'de verilmiştir.

$\mathrm{I}_{0}{ }^{\prime} 1$ hariç tutulursa eğer, $\mathrm{I}_{20}$ sulama konusu sulama suyu randımanı ve sulama suyu kullanımı etkinliği açısından sırasıyla 0.70 ve $1.12 \mathrm{~kg} \mathrm{~m}^{-3}$ değeriyle, sulama konularının sulama suyu randımanı ve sulama suyu kullanımı etkinliği genel ortalaması olan 0.56 ve 0.73 değerlerinin yukarısındadır.

Buradan $\mathrm{I}_{20}$ sulama konusunun diğer konulara kıyasla sulama suyu kullanım etkinliğinin optimum düzeyde olduğu söylenebilir. Uygulanan sulama suyu arttıkça sulama suyu kullanım etkinlik değerinde azalma yönünde bir eğilim belirlenmiştir. 
Tablo 2. Kısıntılı sulama konularına ilişsin hesaplanan bitki su stres indeksi, klorofil içeriği, sulama, evapotranspirasyon, WUE ve IWUE değerleri

\begin{tabular}{|c|c|c|c|c|c|c|}
\hline $\begin{array}{c}\text { Sulama } \\
\text { Konusu }\end{array}$ & $\begin{array}{c}\text { Bitki su stres } \\
\text { indeksi } \\
(\mathrm{CWSI})\end{array}$ & $\begin{array}{c}\text { Klorofil } \\
\text { içeriği } \\
(\mathrm{spad})\end{array}$ & $\begin{array}{c}\text { Sulama } \\
\text { suyu } \\
(\mathrm{mm})\end{array}$ & $\begin{array}{c}\mathrm{ET} \\
(\mathrm{mm})\end{array}$ & $\begin{array}{c}\text { WUE } \\
\left(\mathrm{kg} \mathrm{m}^{-3}\right)\end{array}$ & $\begin{array}{c}\text { IWUE } \\
\left(\mathrm{kg} \mathrm{m}^{-3}\right)\end{array}$ \\
\hline $\mathrm{I}_{0}$ & 0.39 & 36 & 66 & 91 & 2.10 & 1.52 \\
\hline $\mathrm{I}_{20}$ & 0.39 & 36 & 125 & 201 & 0.70 & 1.12 \\
\hline $\mathrm{I}_{40}$ & 0.36 & 39 & 250 & 331 & 0.54 & 0.71 \\
\hline $\mathrm{I}_{60}$ & 0.31 & 41 & 375 & 459 & 0.57 & 0.70 \\
\hline $\mathrm{I}_{80}$ & 0.24 & 44 & 499 & 588 & 0.52 & 0.62 \\
\hline $\mathrm{I}_{100}$ & 0.19 & 48 & 624 & 703 & 0.44 & 0.50 \\
\hline
\end{tabular}

Araştırmacı Çukurova koşullarında PRD 50 konusunda deneme yıllarında en yüksek su kullanım (WUE: $1.0 \mathrm{~kg} \mathrm{~m}^{-3}$ ) ve sulama suyu kullanım randımanı (IWUE: $1.4 \mathrm{~kg} \mathrm{~m}^{-3}$ ) değerini elde etmiştir [14]. Başka bir çalışmada 0.75 ile $1.62 \mathrm{~kg} \mathrm{~m}^{-3}$ bulunmuş iken diğer bir araştırmada ise $1.07-1.43 \mathrm{~kg} \mathrm{~m}^{-3}$ bulunmuştur $[15,16]$. Farklı bölgelerde yürütülen çalışmalar sonucunda elde edilen değerler ile bu çalışmada belirlenen değerler arasinda kısmen de olsa farklılık bulunmaktadır.

Aynı bitkinin farklı bölgelerdeki mevsimlik sulama suyu kullanım etkinliği ve su kullanım etkinliği değerleri arasında gözlenen farklılı̆̆ın; ekim zamanı, iklim etmeni, toprak özellikleri, sulama programı ve kullanılan çeşide bağlı olarak değiştiğinin söylenmesi olasıdır.

Araştırmada, farklı sulama uygulamalarında bitki su stres indeksi (CWSI) değerlerinin 0.19-0.39 arasında değiştiği, en yüksek CWSI değerinin $\mathrm{I}_{0}$ ve $\mathrm{I}_{20}$ sulama konusunda 0.39 olduğu görülmüştür. En düşük CWSI değerinin ise $\mathrm{I}_{100}$ sulama konusunda 0.19 olduğu saptanmıştır. Klorofil içeriği değerlerinin ise 36 spad ile 49 spad arasında değiştiği en yüksek klorofil içeriği değerinin $\mathrm{I}_{100}$ sulama konusunda 49 spad ve en düşük klorofil içeriği değeri ise $\mathrm{I}_{0}$ ve $\mathrm{I}_{20}$ sulama konusunda 36 spad olarak bulunmuştur.

Klorofil içeriği değerlerinin sulama programına bağlı olarak değiştiği kısıntı uygulanan konularda düşük, tam sulanan konuda ise diğerlerine kıyasla daha yüksek olduğunu söylenebilir. CWSI ve klorofil içeriği değerlerinin iklime ve araştırmada kullanılan çeşide göre değişebileceği belirlenmiştir. Yapılan bu çalışmada Siirt koşullarında ayçiçeğinde kısıntılı sulama uygulamalarının tane verimi, bitki boyu, tabla çapı, çiçeklenme gün sayısı (gün). yaprak klorofil içeriği (spad), bitki su stres indeksi, bitki su tüketimi üzerine olan etkileri değerlendirilmiştir. Kısıntılı sulama uygulamalarının, bitkilerde fenolojik olarak değişikliklere neden olduğu söylenebilir.

Tam sulanan konuya kıyasla kısıntı uygulanan sulama konularında bitki boyu, tabla çapı küçülmüş bunun bir sonucu olarak tabladaki tane sayısı azalmış ve tane verimi daha az gerçekleşmiştir. Tam sulama $\left(\mathrm{I}_{100}\right)$ yapılan konuya kıyasla kısıntı uygulanan $\mathrm{I}_{20}$ sulama konusunda yaklaşı $\% 19$ oranında daha az bir verim elde edilmiştir.

$\mathrm{Bu}$ araştırma sonuçlarına göre Siirt koşullarındaki ayçiçeği yetiştiriciliğinde vejetatif gelişme, tabla bağlama, çiçeklenme dönemi ve dane dolum dönemi olmak üzere 4 sulama uygulaması yapılması önerilmektedir. Siirt koşullarında ayçiçeğinde kısıntılı sulama yapılması önerilmemektedir. Eğer kısıntı yapmak zorunluluğu var ise bunun vejetatif gelişme döneminde (çiçeklenme öncesinde) maksimum \%20 oranında yapılması öngörülmektedir.

\section{Teșekkür}

Bu çalışma 9-11 Haziran 2015 tarihleri arasında I. Ulusal Biyosistem Mühendisliği Kongresinde sözlü olarak sunulmuş ve özet olarak bildiri kitabında basılmıştır.

\section{Kaynaklar}

[1] TUIK. Statistics of crop production. Available at www.tuik.gov.tr (Accessed: 15 August 2014), 2013.

[2] Kolsarıcı Ö, Gür A. Başalma D. Kaya MD. İşler, N. Yağlı tohumlu bitkiler üretimi. TMMOB Ziraat Mühendisleri Odası Türkiye Ziraat Mühendisliği VI. Teknik Kongresi, 3-7 Ocak 2005 Ankara,409-429, 2005.

[3] Kaya Y. Evci G. Pekcan V. Gücer, T. ve Durak S. Farklı çevre koşullarında ayçiçeğinde (Helianthus annuus L.) tane verimi ve diğer verim öğeleri arasındaki ilişkilerin belirlenmesi. Trakya Üniversitesi Fen Bilimleri Dergisi, 7(1), 37-44. 2006. 
[4] Gürbüz B. Kaya MD. Demirtola A. Ayçiçeği Tarımı. Hasad Yayıncılık Ltd. Şti. ISBN-975-8377-23-X. Ege Basım, 2003.

[5] İlbas Aİ. Yıldırım B. Arslan B. Dede Ö. Günel E. Van Ekolojik Koşullarında Bazı Ayçiçeği (Helianthus annuus L.) Çeşitlerinin Verimi ve Önemli Tarımsal Özellikleri Üzerinde Bir Araştırma. Yüzüncü Yıl Üniversitesi Ziraat Fakültesi Dergisi, 6 (3),189-203, 1996.

[6] Kadayıfçı A.Yıldırım O. Ayçiçeğinin Su-Verim İlişkileri. Turkish Journal of Agriculture and Forestry, Türk Tarım ve Ormanc1lık Dergisi, C:24, No:2, Ankara, 2000.

[7] Idso SB. Jackson RD. Pinter PJ. Jr. Reginato RJ. and Hatfield JL. Normalizing the stres - degree - day parameter for environmental variability. Agricultural Meteorology,24,45-55, 1982

[8] Jensen ME. Burman RD. and Allen RG. Evapotranspiration and Irrigation Water Requirements. ASCE Manuals and Reports on Engineering Practice No: 70. New York. s. 332, 1990.

[9] Er C. Ayçiçeği Tarımı. Markan Matbaacılık A.Y. İstanbul, 1983.

[10] Erdem T. and Delibaş L. Yield Response of Sunflower to Water Stres Under Tekirdag Conditions. Helia, 26(38),149158, 2003.

[11] Browne CL. Effect of Date of Final Irrigation on Yield and Yield Companents of Sunflower in a Semiarid Environment. Dep. Of Agric.. Leaton. N.S.W. Australian Journal of Experimental Agriculture and Animal Husbandry, 17(86), 482488, 1977.

[12] Unger PW. Irrigation Effect on Sunflower Growth Development and Water Use. USDA Conservation and Production Research Laboratory. Bushland Field Crops Research,7:3,181-194, 1983.

[13] Kaya Y, Evci G. Pekcan V. Gücer T. Yılmaz İM. Ayçiçeğinde yağ verimi ve Bazı verim öğeleri arasında ilişkilerin Belirlenmesi. Tarım Bilimleri Dergisi, 15 (4), 310-318, 2009.

[14] Sezen SM. Yazar A. Tekin S. Kapur B. Konuskan D. Colak Y. Eker S. Akdeniz İklim Kuşağında Kısmi Kök Kuruluğu ve Kısıntılı Sulama Stratejilerinin Ayçiçeği Tane Verimi ve Yağ Kalitesine Etkileri. II. Ulusal Sulama ve Tarımsal Yapılar Sempozyumu, 24-25 Mayıs, İzmir,1-8, 2012.

[15] Kuşçu H. Bursa Koşullarında Yetiştirilen Mısır Bitkisinde Kısıntılı Sulamanın Verim ve Kalite Üzerine Etkisi. Doktora Tezi, Uludağ Üniversitesi, Fen Bilimleri Enstitüsü, Tarımsal Yapılar ve Sulama Ana Bilim Dalı, Bursa, 2010.

[16] Öktem A. Effect of different irrigation intervals to drip irrigated dent corn (Zea mays L.) water-yield relationship. Pakistan Journal of Biological Sciences, 9(8),1476-1481, 2006. 